\title{
eHealth 2015 Special Issue: Effects of an assistance service on the quality of life of elderly users
}

V. Willner'; C. Schneider'; M. Feichtenschlager ${ }^{2}$

${ }^{1}$ Salzburg Research Forschungsgesellschaft m.b.H., MOWI, Salzburg, Austria; ${ }^{2}$ Salzburger Hilfswerk, Salzburg, Austria

\author{
Keywords \\ Aging, assistive technology, quality of life, smartphone
}

\section{Summary}

Background: The 'Confidence' smartphone application aims to support elderly people's independence as long as possible.

Objective: This paper presents first findings on the impact of the system on elderlies' lives. Methods: 41 end-users tested 'Confidence' for six weeks in their daily routine. Before and after the test period the participants assessed their quality of life (QoL). These assessments were analyzed together with additional QoL statements and the usage of 'Confidence' which were collected with questionnaires.

Results: Six participants assessed their QoL after the trial better than before and six participants assessed it as worse. Five individuals felt that 'Confidence' positively influenced their life and these five testers had a positive attitude towards 'Confidence' from the start of the trial. After the trial 38 $\%$ of the participants said that they felt safer, $37 \%$ communicated more with others, $27 \%$ forgot less, $13 \%$ felt better oriented outside, and $7 \%$ were more on the move due to 'Confidence'. Three percent said that they were less on the move, two percent felt more unsafe and two percent were less outside.

Conclusion: 'Confidence' has the potential to affect elderly users' lives. However, within this analysis positive or negative effects of its usage were not correlated with the QoL assessment. A connection between positive attitude towards technology prior use and a positive impact afterwards was found.

\section{Correspondence to:}

Viktoria Willner

Salzburg Research Forschungsgesellschaft m.b.H. Jakob Haringer Straße 5/3

5020 Salzburg, Austria

Email: viktoria.willner@salzburgresearch.at
Appl Clin Inform 2015; 6: 429-442

http://dx.doi.org/10.4338/ACl-2015-03-RA-0033

received: March 30, 2015

accepted in revised form: May 12, 2015

published: July 1, 2015

Citation: Willner V, Schneider C, Feichtenschlager M. Effects of an assistance service on the quality of life of elderly users. Appl Clin Inform 2015; 6: 429-442 http://dx.doi.org/10.4338/ACI-2015-03-RA-0033 


\section{Introduction}

The average age of the world population is increasing [1]. Globally, the number of individuals over 60 is expected to increase from less than 800 million in 2011 (representing $11 \%$ of population) to over two billion in 2050 (representing $22 \%$ of world population). The number and proportion of older people is growing faster than any other age group [1]. This global aging comes with opportunities but also challenges to individuals, families, and societies such as an increase in age related diseases, higher costs for care, and a shortage of caregivers. Technology has potential to address these challenges. Telemedicine or e-health applications may help the elderly to manage their own health and may support caregivers through providing information. Further, technology can enable people to remain connected [2]. Therefore, researchers have recently developed a variety of assistive technologies which support older adults as well as their caregivers. Some services tend to improve safety and mobility; others are aimed at self-management and assistance for daily activities. As $89 \%$ of the elderly prefer to stay in their own homes a common goal of these technologies is helping to age in place [3].

The system presented here addresses the goal of aging in place well. The mobility safeguarding assistance service 'Confidence' is a combination of assistive technologies and personal help which aims at supporting elderly people to stay independent and active as long as possible. It also helps to decrease the burdens for the caregivers. The primary end-users of the 'Confidence' system are elderly with slight cognitive impairments or mild dementia. Daily challenges and problems were identified together with the end-users in order to meet their needs and wishes [4]. Ten use cases were deducted and implemented within five 'Confidence services'. An individually configurable smartphone application designed in collaboration with the primary end-users [5], offers the services as shown in

- Figure 1 .

- Assistance (Call): If a primary end-user needs help in dealing with specific challenges that may arise in his/her daily routine he/she has the possibility to get in contact personally with a caregiver via a voice or video connection.

- Emergency (SOS): In case of an emergency, the SOS button can be pressed. An alert process is activated in the background and the responsible caregiver is informed automatically.

- Environmental info (Weather): Current weather conditions and tips for suitable clothing are provided on demand.

- Daily schedule/reminder (Calendar): This service provides information about tasks and appointments. Reminders for tasks and appointments appear automatically and are read out aloud at a pre-defined time.

- Navigation (Maps): If the primary end-user needs help on his/her way home, he/she can use the service to be guided.

Forty-one primary end-users and their caregivers used the system for six weeks in their daily routine. The objective of this paper is to present initial findings about the impact the 'Confidence smartphone application' use had on the elderlies' lives. Therefore, quality of life (QoL) questionnaires were compared before and after system usage. Statements of users with altered QoL are discussed in detail.

\section{Methods}

\subsection{Field Trials}

To assure the suitability of the system in daily use two field trials were planned. The first field trial was conducted following the first development cycle when a first stable software version was available. It focused on usability and system acceptance. During the second development cycle the software was improved according to the users' feedback. In contrast to the first field trial the second trial aimed at evaluating the effects and impact of the usage of 'Confidence'. Both trials were organized and conducted in the same way. Each time about 120 end-users (elderly people as well as their relatives and caregivers) tested 'Confidence' over a six weeks period in their everyday life in rural 
and urban areas in Romania, Austria, and Switzerland. As of this moment, the second field trial is not yet finished in Romania and evaluation data are not yet available for Switzerland. Therefore, this paper is only focused on the initial findings from the second field trial in Austria.

In Austria, the field trial was conducted both in an urban and a rural region. A total of 19 primary and 19 secondary end-users (seven relatives, six care professionals and six volunteers), who live in the city of Salzburg and the surrounding areas tested the 'Confidence system' over six weeks as representatives of the urban test region. Twenty-two primary end-users and 18 secondary end-users (six relatives, five care professionals, and seven volunteers), who live in the rural region Pongau, participated over six weeks. Table 1 provides information about the primary end-users, who participated at the trial. The cognitive status was evaluated using the Mini-mental State Examination [6]. The age of the participants was between 49 and 89 with a median of 71 .

The trial had been organized following a so called mentor-assistants approach. One care professional was deployed as mentor for the test region. This person was responsible for the complete execution. Further, she had to select, train, and support four to five assistants. Each assistant's task was to introduce 'Confidence' to and support about five primary end-users and their relatives during the trial. Deployed assistants were professionals, who care for the primary end-users beyond the trial. We assumed a better acceptance and motivation to use 'Confidence' if there was a well-known contact person.

\subsection{Evaluation}

In order to measure the effects of the usage of 'Confidence', the trial participants' subjective feelings were recorded at three points (two weeks before the trial, one week after the start and at the end of the trial) with standardized questionnaires mainly based on [7, 8, 9, 10 and 11] and 'Confidencespecific' questions. Before and after the trial users were asked to rate their QoL on a five-point Likert scale ('very poor', 'poor', 'neither poor nor good', 'good' and 'very good'). The evaluation is based mainly on the comparison of the values between the two points in time. Because the QoL is affected by different domains (e.g. social relationships, psychological wellbeing, health, social roles and activities, and independence) $[12,13]$, it cannot be concluded that the usage of 'Confidence' alone induced a chang. The most relevant aspects for the trial participants were identified through the openended question "What does quality of life mean for you?" before the trial. In addition to the assessment of QoL in general, the participants rated their satisfaction with their own health [8] before and after the trial as well as problems to execute usual activities [7] before the trial.

After the trial the subjective feelings about the influence 'Confidence' on the daily life of the participants were recorded ('positive', 'negative,' 'no influence'). We assumed that the attitude towards 'Confidence' and the specific services at the beginning of the trial correlated with the influence on daily living and the QoL afterwards. So, the attitude towards 'Confidence' and the estimation of the usefulness of the services was evaluated one week after its use started. Most liked features and their rating after one week of use and at the end of the trial were compared. The willingness to continue using the system after the trial was evaluated.

Additionally, the influences of the individual 'Confidence services' were surveyed through subjective changes in the feeling of safety, mobility, orientation, communication, and cognitive abilities. These measures can be crosschecked with the personal aspects on QoL of the participants. E.g. if mobility is an important QoL-aspect of a participant, and he had the feeling to be more on the move with 'Confidence' later and his QoL value improved, we can infer that 'Confidence' made a contribution.

\section{Results}

A total of 41 subjects finished the test period of six weeks in the two Austrian test regions. Participants rated their QoL before and after the trial. Table 2 presents the comparison of the QoL values and shows that six persons rated their QoL better (indicated with $\uparrow$ ) and six persons rated their QoL worse (indicated with $\downarrow$ ). Additionally the table shows the satisfaction with the health before and after the trial $(1$ = very dissatisfied, 2 = dissatisfied, 3 = neither satisfied nor dissatisfied, $4=$ satisfied, 
5 = very satisfied). Four people with a better QoL value also stated more satisfaction with health (subjects 5, 10, 20,22). Of individuals with a worse QoL, one value rated the satisfaction with health worse (subject 7) and one person rated it better (subject 29). The others with an altered QoL value rated their satisfaction with health the same before and after the trial. The table further shows the ability to conduct usual activities. This information was collected in the beginning of the trial $(1=$ no problems, 2 = slight problems, 3 = moderate problems, $4=$ severe problems, $5=$ unable to do).

The evaluation of answers to the open-question "What does quality of life mean for you?" showed that the most relevant aspects to QoL with regard to 'Confidence testers' were health (18 out of 41 18/41) autonomy (13/41), mobility (13/42) and financial security (9/41).After one week of testing, participants answered questions about the first impression of 'Confidence' and its usefulness. $>$ Figure 2 shows the general impression of the participants. Table 3 shows that five persons with a better QoL value liked 'Confidence' and one didn't like it. Three persons with a worse QoL value were neutral about 'Confidence', two persons liked it very much and one person didn't like it. $>$ Figure 3 presents how the participants rated the usefulness of 'Confidence' after one week of use. - Table 4 shows that five persons with improved QoL value found 'Confidence' useful; one found it not much useful. Two persons with a worse QoL said 'Confidence' is useful for them, two were neutral and two preceived it as not useful.

Users were asked to evaluate which features were useful and which not. > Figure 4 shows which functions were useful for the trial participants. After one week of use the calendar/reminder function was perceived as the most useful function and the video call was the least useful function.

- Table 5 shows that most of the persons with altered QoL value found the calendar and SOS function useful. The video function was not rated or seen as not useful. The map and weather function had mixed reviews.

After one week of use and after the trial the participants were asked which functions they like best. Additionally they were asked which of the services they would like to continue to use. In the beginning testers liked the calendar function best. At the end of the trial the preferred feature was replaced by the call function and the SOS function which were not liked much in the beginning ( $>$ Figure 5).

The distribution of the most liked functions looks similar for the persons with altered QoL value. - Table 6 shows that after one week of testing the calendar function was mentioned most frequently. The other features were mentioned four times. After the trial the call function was mentioned most, closely followed by SOS and calendar functions. The grey marked fields indicate changes between test start and test end.

- Figure 6 and $>$ Table 7 show that the call, SOS and calendar/reminder functions are most frequently mentioned when we asked which functions the participants would like to continue to use after the trial.

After the trial period $35 \%$ of the participants stated that 'Confidence' had a positive influence on their everyday life, $7 \%$ indicated a negative influence, and $58 \%$ said that 'Confidence' had no influence on their life ( $>$ Figure 7 ). Four persons with a better QoL value said, that 'Confidence' positively influenced their life; two said that the usage had no influence. One person with a worse QoL value said that 'Confidence' positively influenced his life; one said it negatively influenced his life, and four persons said that 'Confidence' had no influence ( $>$ Table 8).

Further the participants were asked about the influences 'Confidence' could have in detail. $>$ Figure 8 shows that $38 \%$ felt safer, $7 \%$ were more on the move, $13 \%$ felt better oriented outside, $37 \%$ communicated more with others, and $27 \%$ forgot less due to 'Confidence. Two percent felt more unsafe, $3 \%$ were less on the move, and $2 \%$ were less outside due to 'Confidence'.

Table 9 shows that the participants with altered QoL mainly reported no changes $(\leftrightarrow)$ and most of them (8/12) reported at least one positive effect of the usage of 'Confidence' $(\uparrow)$. Five said that they felt safer; one said that he was more on the move; two said that they felt better oriented; five said that they communicated more with others and four said that they forgot less due to 'Confidence. One said that he felt worse oriented outside with 'Confidence' $(\downarrow)$. 


\section{Discussion}

This paper presents the influences 'Confidence' had on elderly peoples' lives. Twelve out of 41 people, who tested the service during six weeks, were analyzed in detail (six assessed their QoL better and six assessed it as worse). Five of these people had the feeling that 'Confidence' positively influenced their daily living. All of the subjects had a positive attitude towards 'Confidence' from the start of the trial, stating they liked or liked the service very much and considered it useful ( Table 3, - Table 4). Different statements in connection with positive influence were made after the trial. Persons who said that they felt safer would also like to continue to use the SOS function ( Table 9, - Table 6). Persons who felt that they communicated more with others would like to continue to use the call function and persons who felt they forget less would like to continue to use the calendar / reminder function. One person said that 'Confidence' had a negative influence on his daily living. From the start of trial he had a rather negative attitude towards 'Confidence'. He felt that the service is not useful and he neither liked it nor disliked it. Further his satisfaction with health changed from 'satisfied' before the trial to 'dissatisfied' after the trial. The user did not state any special negative effects after the trial. He had the feeling to forget less and would like to continue to use the call function. Six testers said that 'Confidence' had not affected their lives. Two of these users rated their QoL better and four of them worse. Two users with a worse QoL value reported that they communicated more with others due to 'Confidence' and one added that he forgot less. The other four persons did not report any changes concerned to 'Confidence.'

\section{Conclusion}

We conclude that assistive technologies have the potential to affect elderly users' lives. Although 'Confidence' addresses different quality of life domains (e.g. social relationships, psychological wellbeing, independence, health), positive or negative effects of its usage are not always correlated with a better or worse assessment of quality of life within this analysis. A connection between a positive attitude at the beginning of the trail and the subjective feeling of positive influence is given. Further the evaluation showed a correlation between addressed need (e.g. better feeling of safety) and the aim to continue to use a specific function (e.g. SOS). We conclude that the 'Confidence services' are well designed and fulfill their purpose. Although, initial findings about the effects are encouraging, the number of users was too small to prove a correlation between quality of life and the effects 'Confidence' may have on users' lives. The evaluation of the collected data of the ongoing field trial in Switzerland and Romania will provide additional understanding. Moreover, conducting comparative trials with a control group would be useful.

\section{Clinical Relevance}

This paper adds to the growing research field of 'Active and Assisted Living' through findings of a six weeks field trial, which went beyond feasibility and usability by adding QoL measures. Effects of the system usage and influences on the daily living of elderlies are presented and may help researchers to develop applications and evalute them using methodologies from this trial.

\section{Conflict of Interest}

The authors declare that they have no conflict of interest in the research.

\section{Human Subjects Protections}

The procedures used have been reviewed in compliance with ethical standards of the responsible committee on ethics and data protection commission.

\section{Acknowledgments}

The work carried out in Confidence (http://www.confidence4you.eu) is supported by the European Commission within the Ambient Assisted Living Joint Programme. Special thanks go to all members of the Confidence team for their contributions within the testing phase 


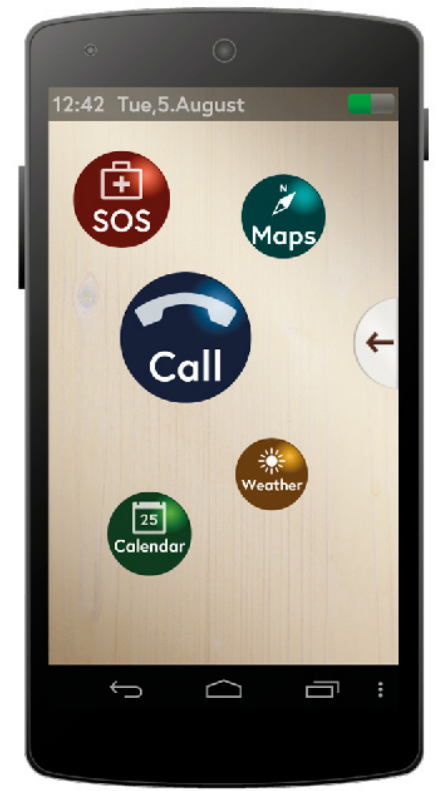

Fig. 1 Confidence application

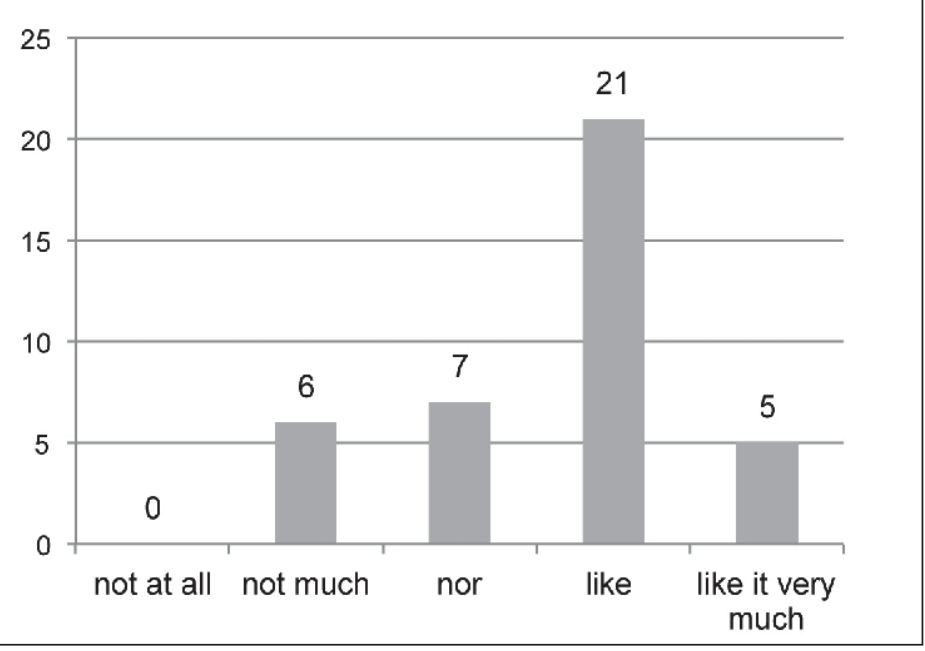

Fig. 2 How do you like Confidence in general? $(n=39)$

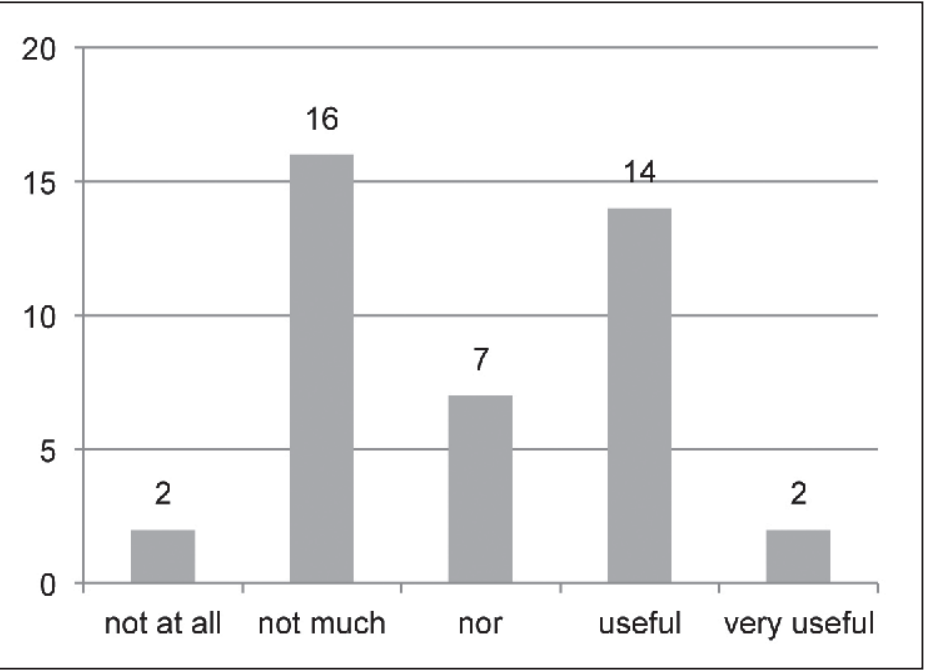

Fig. 3 How useful is Confidence for you currently? ( $n=41$ ) 


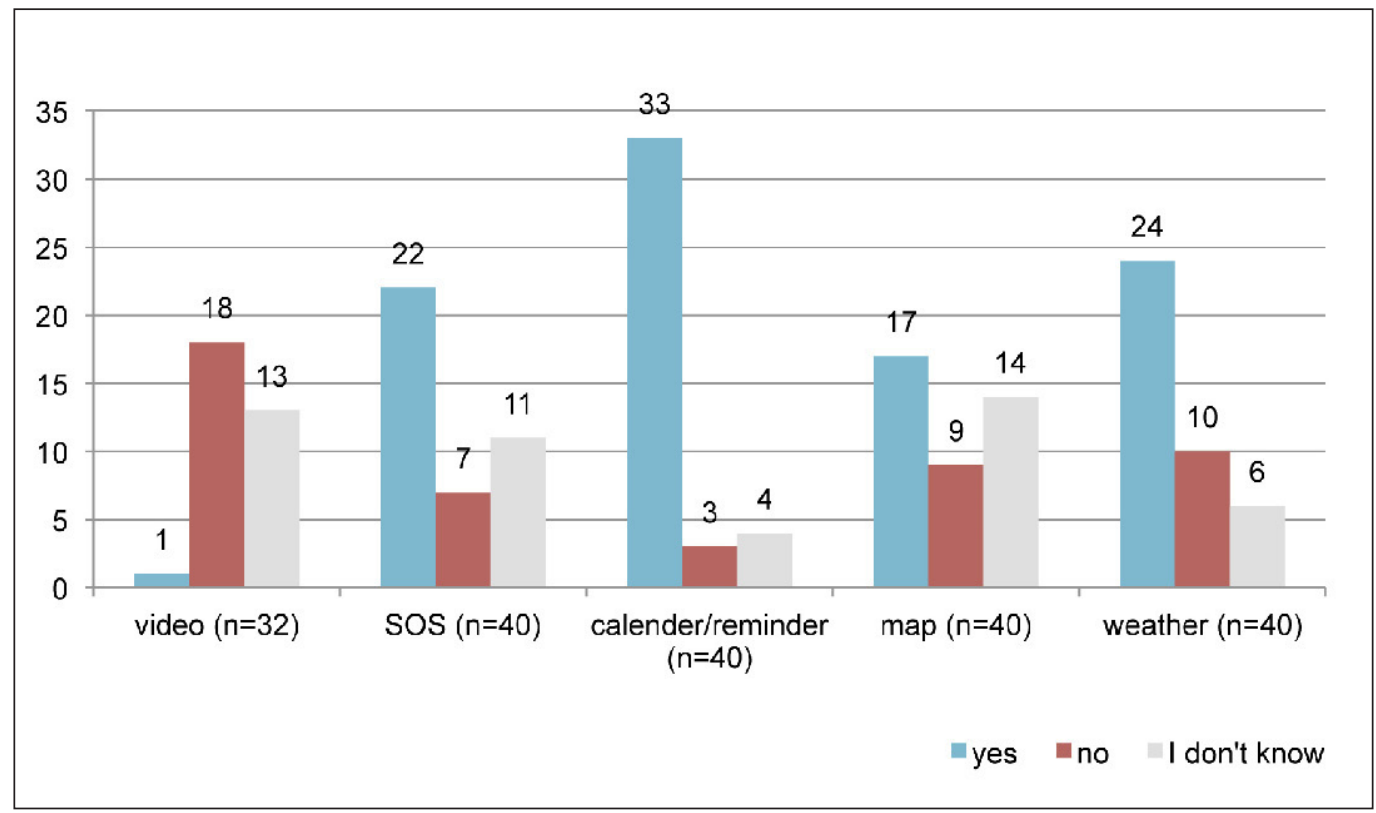

Fig. 4 Is the function ... useful?

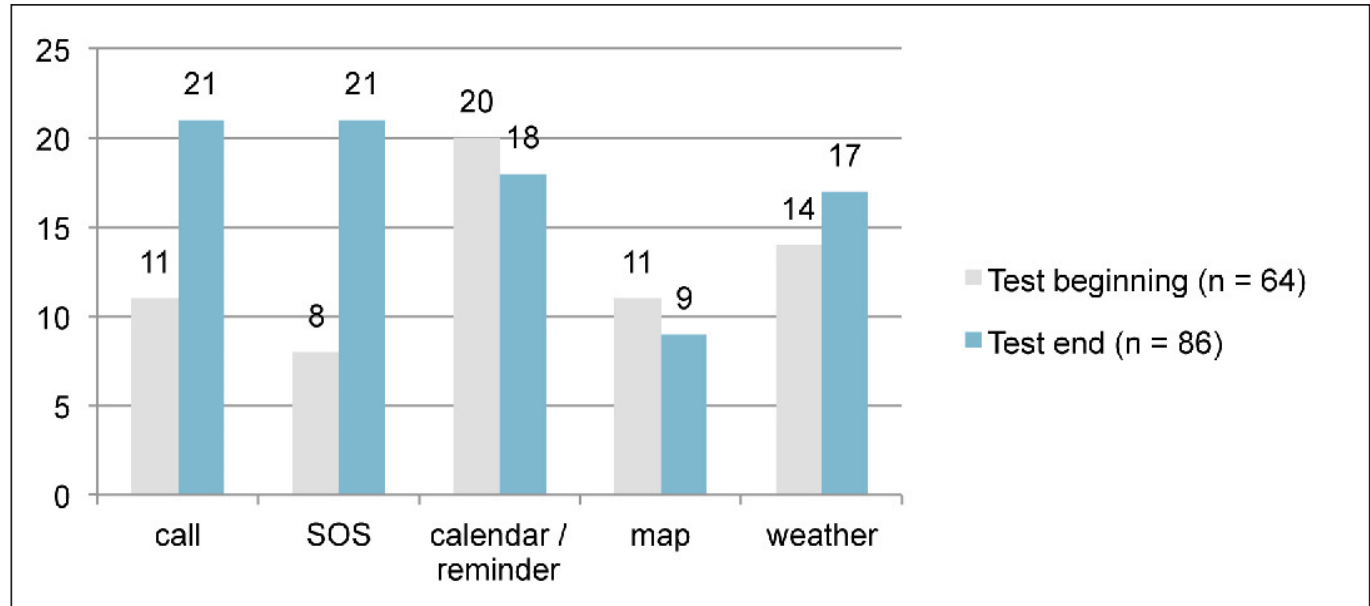

Fig. 5 Which function do you like best?

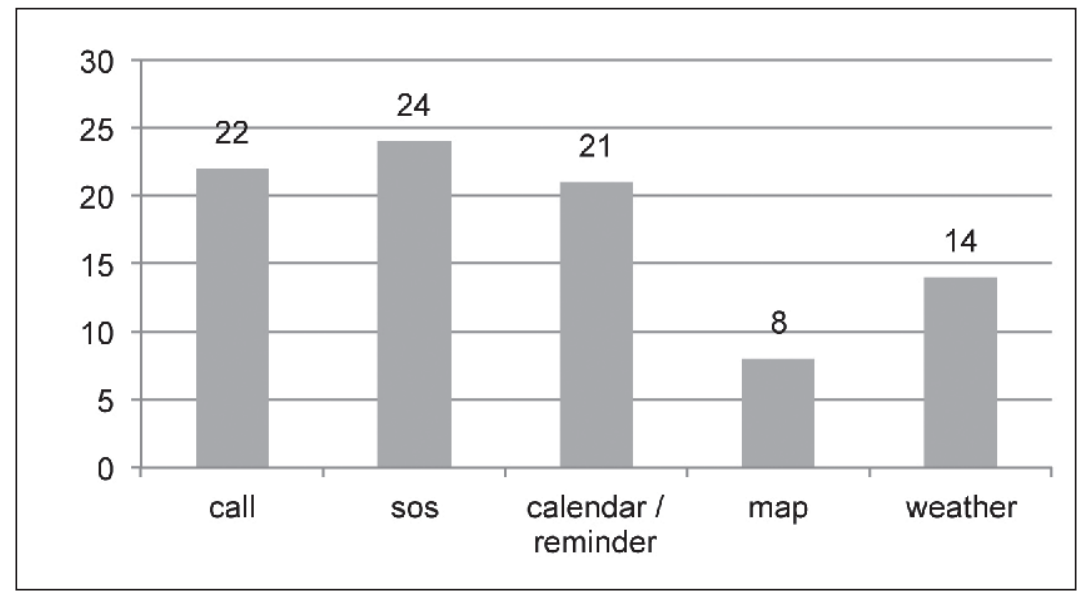

Fig. 6 Which function would you like to continue to use? 


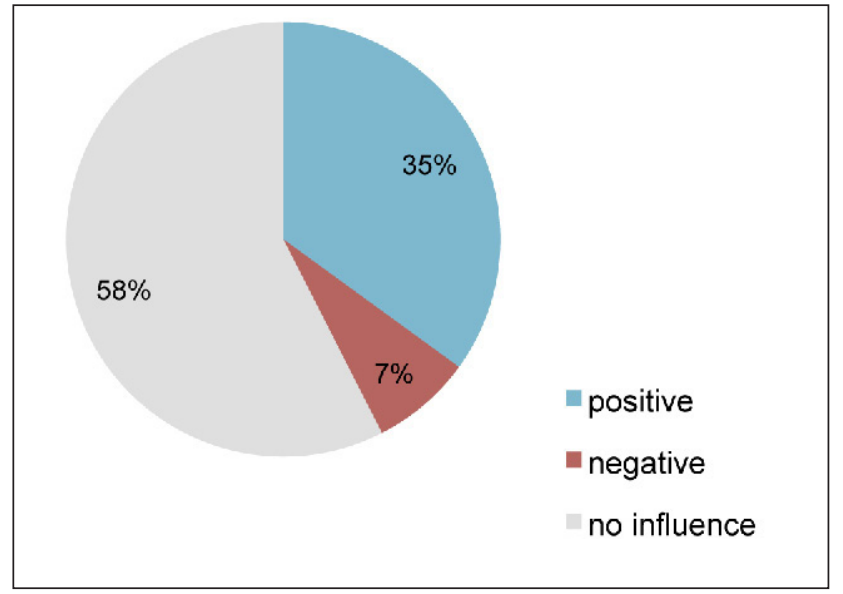

Fig. 7 Did Confidence affect your everyday life? $(n=40)$

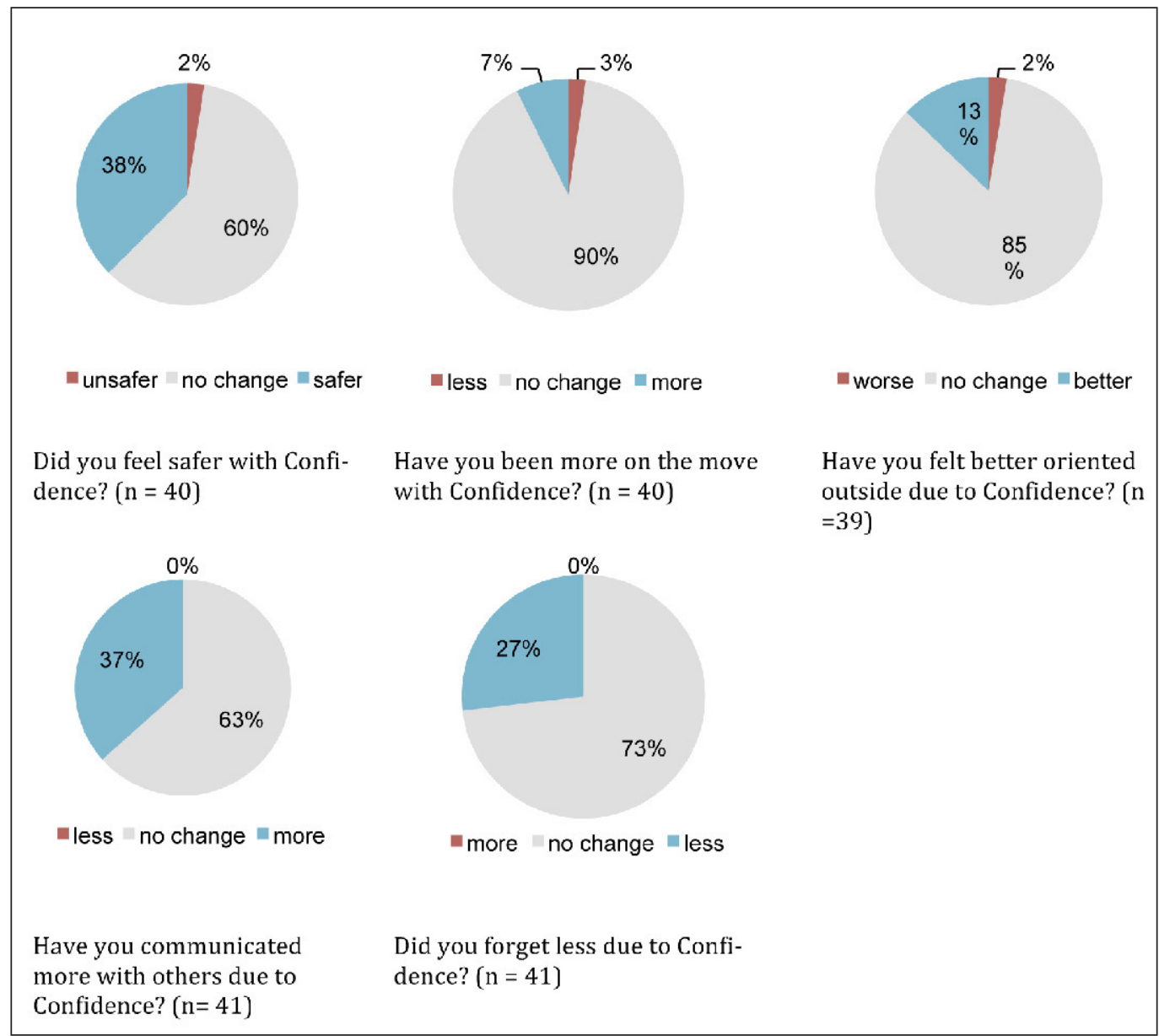

Fig. 8 Confidence' effects 
Table 1 Primary end users

\begin{tabular}{|l|l|l|l|l|}
\hline & & Total & Urban Region & Rural Region \\
\hline Number & Male & 41 & 19 & 22 \\
\hline Gender & 12 & 4 & 8 \\
\hline MMSE & 29 & 15 & 14 \\
\hline $\begin{array}{l}\text { Female } \\
\text { Normal cognitive } \\
\text { function }\end{array}$ & 34 & 13 & 21 \\
\hline $\begin{array}{l}\text { Mild cognitive im- } \\
\text { pairment }\end{array}$ & 4 & 3 & 1 \\
\hline $\begin{array}{l}\text { Moderate cognitive } \\
\text { impairment }\end{array}$ & 1 & 1 & 0 \\
\hline \begin{tabular}{l} 
No value \\
\hline
\end{tabular} & 2 & 2 & 0 \\
\hline
\end{tabular}

Table 2 Quality of life assessment

\begin{tabular}{|c|c|c|c|c|c|c|}
\hline \multirow{2}{*}{\multicolumn{2}{|c|}{$\begin{array}{l}\text { Subject } \\
\text { number }\end{array}$}} & \multicolumn{2}{|c|}{ Satisfaction with QoL } & \multicolumn{2}{|c|}{ Satisfaction with health } & \multirow{2}{*}{$\begin{array}{l}\text { Problems in doing } \\
\text { usual activities }\end{array}$} \\
\hline & & Test beginning & Test end & Test beginning & Test end & \\
\hline & 1 & 4 & 4 & 4 & 4 & 1 \\
\hline & 2 & 3 & 3 & 4 & 4 & 1 \\
\hline & 3 & 4 & 4 & 4 & 4 & 2 \\
\hline & 4 & 4 & 4 & 4 & 4 & 1 \\
\hline$\uparrow$ & 5 & 3 & 4 & 2 & 4 & 2 \\
\hline$\downarrow$ & 6 & 3 & 2 & 1 & 1 & 5 \\
\hline \multirow[t]{3}{*}{$\downarrow$} & 7 & 4 & 3 & 4 & 2 & 1 \\
\hline & 8 & 5 & 5 & 5 & 4 & 1 \\
\hline & 9 & 4 & 4 & 2 & 4 & 4 \\
\hline \multirow[t]{4}{*}{$\uparrow$} & 10 & 3 & 4 & 3 & 4 & 2 \\
\hline & 11 & 4 & 4 & 4 & 4 & 2 \\
\hline & 12 & 4 & 4 & 4 & 3 & 2 \\
\hline & 13 & 4 & 4 & 4 & 4 & 1 \\
\hline \multirow[t]{3}{*}{$\uparrow$} & 14 & 3 & 4 & 3 & 3 & 2 \\
\hline & 15 & 4 & 4 & 5 & 4 & 2 \\
\hline & 16 & 4 & 4 & 4 & 4 & 5 \\
\hline \multirow[t]{3}{*}{$\downarrow$} & 17 & 5 & 4 & 4 & 4 & 5 \\
\hline & 18 & 5 & 5 & 5 & 4 & 1 \\
\hline & 19 & 4 & 4 & 4 & 4 & 1 \\
\hline \multirow[t]{2}{*}{$\uparrow$} & 20 & 2 & 4 & 2 & 3 & 3 \\
\hline & 21 & 4 & 4 & 4 & 4 & 2 \\
\hline \multirow[t]{2}{*}{$\uparrow$} & 22 & 3 & 4 & 3 & 4 & l \\
\hline & 23 & 3 & 3 & 3 & 3 & I \\
\hline \multirow[t]{2}{*}{$\downarrow$} & 24 & 3 & 2 & 2 & 2 & 3 \\
\hline & 25 & 1 & 1 & 2 & 2 & 3 \\
\hline$\uparrow$ & 26 & 2 & 4 & 1 & 1 & 4 \\
\hline
\end{tabular}


Table 2 Continued

\begin{tabular}{|c|c|c|c|c|c|c|}
\hline \multirow{2}{*}{\multicolumn{2}{|c|}{$\begin{array}{l}\text { Subject } \\
\text { number }\end{array}$}} & \multicolumn{2}{|c|}{ Satisfaction with QoL } & \multicolumn{2}{|c|}{ Satisfaction with health } & \multirow{2}{*}{$\begin{array}{l}\text { Problems in doing } \\
\text { usual activities }\end{array}$} \\
\hline & & Test beginning & Test end & Test beginning & Test end & \\
\hline & 27 & 4 & 4 & 4 & 4 & 1 \\
\hline & 28 & 5 & 5 & 5 & 4 & 1 \\
\hline \multirow[t]{4}{*}{$\downarrow$} & 29 & 5 & 4 & 4 & 5 & 1 \\
\hline & 30 & 4 & 4 & 4 & 4 & 2 \\
\hline & 31 & 4 & 4 & 4 & 5 & 2 \\
\hline & 32 & 4 & 4 & 4 & 4 & 1 \\
\hline \multirow[t]{9}{*}{$\downarrow$} & 33 & 4 & 3 & 4 & 4 & 2 \\
\hline & 34 & 3 & 3 & 3 & 3 & 3 \\
\hline & 35 & 4 & 4 & 5 & I & 1 \\
\hline & 36 & 3 & 3 & 3 & 3 & 3 \\
\hline & 37 & 4 & 4 & 3 & 3 & 2 \\
\hline & 38 & 4 & 4 & 4 & 4 & 1 \\
\hline & 39 & 4 & 4 & 3 & 4 & 2 \\
\hline & 40 & 4 & 4 & 4 & 4 & 2 \\
\hline & 41 & 4 & 4 & 4 & 4 & 1 \\
\hline
\end{tabular}

\begin{tabular}{|l|l|l|}
\multicolumn{2}{l}{ Subject } & How \\
$\uparrow$ & 5 & Like \\
\hline$\uparrow$ & 10 & Like \\
\hline$\uparrow$ & 14 & Like \\
\hline$\uparrow$ & 20 & Not much \\
\hline$\uparrow$ & 22 & Like \\
\hline$\uparrow$ & 26 & Like \\
\hline$\downarrow$ & 6 & Like it very much \\
\hline$\downarrow$ & 7 & Nor \\
\hline$\downarrow$ & 17 & Like it very much \\
\hline$\downarrow$ & 24 & Nor \\
\hline$\downarrow$ & 29 & Not much \\
\hline$\downarrow$ & 33 & Nor \\
\hline
\end{tabular}

Table 3 Impressions of investigated subjects 


\begin{tabular}{|l|l|l|}
\multicolumn{2}{|c|}{ Subject number } & How useful is Confidence for you currently? \\
\hline$\uparrow$ & 5 & Useful \\
\hline$\uparrow$ & 10 & Useful \\
\hline$\uparrow$ & 14 & Useful \\
\hline$\uparrow$ & 20 & Not much \\
\hline$\uparrow$ & 22 & Useful \\
\hline$\uparrow$ & 26 & Useful \\
\hline$\downarrow$ & 6 & Useful \\
\hline$\downarrow$ & 7 & Not much \\
\hline$\downarrow$ & 17 & Nor \\
\hline$\downarrow$ & 24 & Useful \\
\hline$\downarrow$ & 29 & Not much \\
\hline$\downarrow$ & 33 & Nor \\
\hline
\end{tabular}

Table 4 Ratings of investigated subjects

Table 5 Useful features for investigated subjects

\begin{tabular}{|c|c|c|c|c|c|c|}
\hline \multicolumn{2}{|c|}{$\begin{array}{l}\text { Subject } \\
\text { number }\end{array}$} & \multirow{2}{*}{$\begin{array}{l}\text { Video } \\
/\end{array}$} & \multirow{2}{*}{$\begin{array}{l}\text { SOS } \\
\text { Yes }\end{array}$} & \multirow{2}{*}{$\begin{array}{l}\text { Calendar / } \\
\text { reminder } \\
\text { Yes }\end{array}$} & \multirow{2}{*}{$\begin{array}{l}\text { Map } \\
\text { Yes }\end{array}$} & \multirow{2}{*}{$\begin{array}{l}\text { Weather } \\
\text { Yes }\end{array}$} \\
\hline$\uparrow$ & 5 & & & & & \\
\hline$\uparrow$ & 10 & I don't know & I don't know & I don't know & I don't know & I don't know \\
\hline$\uparrow$ & 14 & No & Yes & Yes & No & Yes \\
\hline$\uparrow$ & 20 & No & No & Yes & No & No \\
\hline$\uparrow$ & 22 & I & Yes & Yes & Yes & No \\
\hline$\uparrow$ & 26 & I & Yes & Yes & Yes & Yes \\
\hline$\downarrow$ & 6 & No & I don't know & Yes & Yes & Yes \\
\hline$\downarrow$ & 7 & No & Yes & Yes & Yes & Yes \\
\hline$\downarrow$ & 17 & I & Yes & Yes & Yes & Yes \\
\hline$\downarrow$ & 24 & I & Yes & Yes & I don't know & Yes \\
\hline$\downarrow$ & 29 & No & No & Yes & I don't know & No \\
\hline$\downarrow$ & 33 & I don't know & Yes & Yes & I don't know & I don't know \\
\hline
\end{tabular}


Table 6 Which function do you like best?

\begin{tabular}{|c|c|c|c|c|c|c|c|c|c|c|c|}
\hline \multirow{2}{*}{\multicolumn{2}{|c|}{$\begin{array}{l}\text { Subject } \\
\text { number }\end{array}$}} & \multicolumn{5}{|c|}{ Test beginning } & \multicolumn{5}{|c|}{ Test end } \\
\hline & & \multirow{2}{*}{$\begin{array}{c}\text { call } \\
x\end{array}$} & \multirow{2}{*}{$\begin{array}{c}\text { SOS } \\
x\end{array}$} & \multirow{2}{*}{$\begin{array}{c}\text { calendar } \\
\mathrm{x}\end{array}$} & \multirow{2}{*}{$\begin{array}{c}\text { map } \\
x\end{array}$} & \multirow{2}{*}{$\begin{array}{c}\text { weather } \\
x\end{array}$} & \multirow[t]{2}{*}{ call } & \multirow[t]{2}{*}{ SOS } & \multirow[t]{2}{*}{ calendar } & \multirow{2}{*}{$\begin{array}{c}\text { map } \\
x\end{array}$} & \multirow{2}{*}{$\begin{array}{c}\text { weather } \\
x\end{array}$} \\
\hline$\uparrow$ & 5 & & & & & & & & & & \\
\hline$\uparrow$ & 10 & $x$ & & & & & $x$ & & & & \\
\hline$\uparrow$ & 14 & & & $x$ & & & & & $x$ & & $x$ \\
\hline$\uparrow$ & 20 & $x$ & & $x$ & & & $x$ & & $\mathrm{x}$ & & \\
\hline$\uparrow$ & 22 & & & $x$ & $x$ & & & $x$ & & & \\
\hline$\uparrow$ & 26 & & & $x$ & & & $x$ & $x$ & $x$ & & \\
\hline$\downarrow$ & 6 & & & $x$ & $x$ & $x$ & $x$ & $x$ & $x$ & & $x$ \\
\hline$\downarrow$ & 7 & & & & & $x$ & $x$ & & & & \\
\hline$\downarrow$ & 17 & $x$ & $x$ & $x$ & $x$ & $x$ & $x$ & $x$ & $x$ & $x$ & $x$ \\
\hline$\downarrow$ & 24 & & $x$ & & & & & $x$ & & & \\
\hline$\downarrow$ & 29 & & & $x$ & & & & & $x$ & & \\
\hline$\downarrow$ & 33 & & $x$ & & & & $x$ & $x$ & & & \\
\hline
\end{tabular}

Table 7 Would you like to continue to use?

\begin{tabular}{|c|c|c|c|c|c|c|}
\hline \multicolumn{2}{|c|}{ Subject number } & \multirow[t]{2}{*}{ Video } & \multirow{2}{*}{$\begin{aligned} \text { SOS } & \\
& x \\
& \end{aligned}$} & \multirow{2}{*}{$\begin{array}{l}\text { Calendar I } \\
\text { reminder }\end{array}$} & \multirow{2}{*}{$\begin{array}{r}\text { Map } \\
\text { x }\end{array}$} & \multirow{2}{*}{$\begin{array}{r}\text { Weather } \\
\text { x }\end{array}$} \\
\hline$\uparrow$ & 5 & & & & & \\
\hline$\uparrow$ & 10 & $x$ & $\mathrm{x}$ & & & \\
\hline$\uparrow$ & 14 & & & $x$ & & \\
\hline$\uparrow$ & 20 & $x$ & $x$ & $\mathrm{x}$ & & \\
\hline$\uparrow$ & 22 & & $x$ & & & \\
\hline$\uparrow$ & 26 & $x$ & $x$ & $x$ & & \\
\hline$\downarrow$ & 6 & $\mathrm{x}$ & $x$ & $x$ & & $x$ \\
\hline$\downarrow$ & 7 & $x$ & & & & \\
\hline$\downarrow$ & 17 & $x$ & $x$ & $x$ & $x$ & $x$ \\
\hline$\downarrow$ & 24 & $x$ & $x$ & $x$ & & \\
\hline$\downarrow$ & 29 & & & $x$ & & \\
\hline$\downarrow$ & 33 & & $x$ & & & \\
\hline
\end{tabular}




\begin{tabular}{|l|l|l|}
\multicolumn{2}{|l}{ Subject number } & Did Confidence affect your everyday life? \\
\hline$\uparrow$ & 5 & Yes, positive \\
\hline$\uparrow$ & 10 & Yes, positive \\
\hline$\uparrow$ & 14 & Yes, positive \\
\hline$\uparrow$ & 20 & No, no influence \\
\hline$\uparrow$ & 22 & No, no influence \\
\hline$\uparrow$ & 26 & Yes, positive \\
\hline$\downarrow$ & 6 & Yes, positive \\
\hline$\downarrow$ & 7 & Yes, negative \\
\hline$\downarrow$ & 17 & No, no influence \\
\hline$\downarrow$ & 24 & No, no influence \\
\hline$\downarrow$ & 29 & No, no influence \\
\hline$\downarrow$ & 33 & No, no influence \\
\hline
\end{tabular}

Table 8 Confidence's influence

Table 9 Confidence' effects

\begin{tabular}{|l|l|l|l|l|l|l|}
\hline $\begin{array}{l}\text { Subject } \\
\text { number }\end{array}$ & $\begin{array}{l}\text { Feeling of } \\
\text { safety }\end{array}$ & On the move & Orientation & $\begin{array}{l}\text { Communi- } \\
\text { cation }\end{array}$ & Forgetfulness \\
\hline$\uparrow$ & 5 & $\uparrow$ & $\leftrightarrow$ & $\downarrow$ & $\leftrightarrow$ & $\leftrightarrow$ \\
\hline$\uparrow$ & 10 & $\uparrow$ & $\leftrightarrow$ & $\uparrow$ & $\uparrow$ & $\leftrightarrow$ \\
\hline$\uparrow$ & 14 & $\leftrightarrow$ & $\leftrightarrow$ & $\leftrightarrow$ & $\leftrightarrow$ & $\leftrightarrow$ \\
\hline$\uparrow$ & 20 & $\leftrightarrow$ & $\leftrightarrow$ & $\leftrightarrow$ & $\leftrightarrow$ & $\leftrightarrow$ \\
\hline$\uparrow$ & 22 & $\leftrightarrow$ & $\leftrightarrow$ & $\leftrightarrow$ & $\uparrow$ & $\uparrow$ \\
\hline$\uparrow$ & 26 & $\uparrow$ & $\leftrightarrow$ & $\leftrightarrow$ & $\uparrow$ & $\uparrow$ \\
\hline$\downarrow$ & 6 & $\uparrow$ & $\uparrow$ & $\uparrow$ & $\leftrightarrow$ & $\leftrightarrow$ \\
\hline$\downarrow$ & 7 & $\leftrightarrow$ & $\leftrightarrow$ & $\leftrightarrow$ & $\leftrightarrow$ & $\leftrightarrow$ \\
\hline$\downarrow$ & 17 & $\uparrow$ & $\leftrightarrow$ & $\leftrightarrow$ & $\leftrightarrow$ & $\leftrightarrow$ \\
\hline$\downarrow$ & 24 & $\leftrightarrow$ & $\leftrightarrow$ & $\leftrightarrow$ & $\leftrightarrow$ & $\leftrightarrow$ \\
\hline$\downarrow$ & 29 & $\leftrightarrow$ & $\leftrightarrow$ & $\leftrightarrow$ & $\leftrightarrow$ & $\leftrightarrow$ \\
\hline$\downarrow$ & 33 & $\leftrightarrow$ & $\leftrightarrow$ & $\leftrightarrow$ & $\leftrightarrow$ & $\leftrightarrow$ \\
\hline
\end{tabular}




\section{References}

1. Bloom DE, Boersch-Supan A, McGee P, Seike A. Population aging: facts, challenges, and responses. Benefits and Compensation International 2011; 41(1): 22.

2. Czaja SJ, Sharit J. The aging of the population: Opportunities and challenges for human factors engineering. The Bridge: Linking Engineering and Society 2009; 39(1): 34-40.

3. Parisa R, Mihailidis A. A survey on ambient-assisted living tools for older adults. IEEE journal of biomedical and health informatics 2013; 17(3): 579-590.

4. Schneider C, Willner V, Feichtenschlager M, Andrushevich A, Spiru L. Collecting user requirements for electronic assistance for people with dementia: a case study in three countries. Proceedings of the eHealth 2013, Ammenwerth E., Hörbst A., Hayn D., Schreier G., eds., Vienna: OCG. 2013; 107-112.

5. Willner V, Schneider C, Kistler R, Feichtenschlager M, Spiru L, Turcu I, Meyer T. Wishes and Desires of End Users Regarding a Mobility Safeguarding Assistance Service for People with Dementia. In: Pohjanen E, editor. Impacting Individuals, Society and Economic Growth, Proceedings of the 5th AAL Forum 2013; 71-77.

6. Folstein MF, Folstein SE, McHugh PR. "Mini-mental state": a practical method for grading the cognitive state of patients for the clinician. Journal of psychiatric research 1975; 12(3): 189-198.

7. Oemar M, Janssen B. EQ-5D-5L User Guide. [cited 2015 Jan 16]. Available from: www.euroqol.org.

8. who.int [Internet]. WHOQOL-BREF. [cited 2015 Jan 16]. Available from: http://www.who.int/sub stance_abuse/research_tools/whoqolbref/en/.

9. Karrer K, Glaser C, Clemens C, Bruder C. Technikaffinität erfassen- der Fragbogen TA-EG. Der Mensch im Mittelpunkt technischer Systeme 2009; 8: 196-201. German.

10. Trukeschitz B, Sengschmid T, Schneider U. Versteckte Kosten der Angehörigenpflege: die psychosoziale Belastungen pflegender Angehöriger. Elder Care (Altenpflege). Intersektionelle Analysen der informellen Betreuung und Pflege alter Menschen in Österreich. Hrsg. E. Appelt; E. Fleischer; M. Preglau, Innsbruck: Studienverlag 2014; 113-130. German.

11.Lewis JR. Computer Usability Satisfaction Questionnaires: Psychometric Evaluation and Instructions for Use. IBM Technical Report 1993; 54: 786.

12.Zahava G, Bowling A. Quality of life from the perspectives of older people. Ageing and Society. 2004; 24.05: 675-691.

13. Netuveli G, Blane D. Quality of life in older ages. British medical bulletin. 2008; 85(1): 113-126. 